Journal Of Al Azhar University Engineering Sector

Vol. 11, No. 39, April 2016, 557- 570

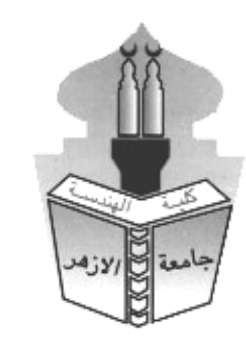

\title{
COMPARATIVE STUDY BETWEEN DIFFERENT METHODS USED IN PROTECTION BY DISTANCE OF ELECTRICAL NETWORKS
}

\begin{abstract}
Dept. of Electrical Engineering, Al-Azhar Univ.

Distance relays (D.R) are used in protection of electrical networks to measure the apparent impedance of the fault and shall compare it with its D.R setting impedance, but the apparent impedance may be differ from the actual impedance due to the network challenges appeared such as effect of branched networks, series capacitor for compensation, power swing, parallel transmission lines and fault resistance. All of these challenges will result to overreach or underreach errors, accordingly false trip. Some of approach methods shall be introduced in this paper to overcome these errors. In the recent transmission line (T.L) systems, more than one of these challenges can appear simultaneously. It shall be difficult to adjust the D.R with value suitable for all challenges. In this paper, the study how D.R will overcome each challenge alone and how it will be adjusted with value suitable for all of these challenges together shall be considered.
\end{abstract}

S. M. Ali, A. M. Abdel-Aziz and R. A .Refai

KEYWORDS: Distance Relay; Overreach And Underreach Errors; Multi Terminal Line;

Parallel Lines; Series Capacitors; Power Swing; Fault And Load Resistance.

\section{INTRODUCTION}

In the past, fault elimination in the networks irrespective of the security or dependability problems was considered. When the loads have increased and the network became extensive, it was important to eliminate the fault in narrow section. Mal-operation of D.R used for protection was due to number of challenges in the network. These challenges may cause the D.R measured impedance differ from the actual impedance, accordingly overreach or underreach errors in D.R measurements.

In the last century most of researches studied the using of D.Rs considering one challenge. Now, in recent and advanced networks there are more than one challenge may occurs in the network at the same time. Power swings due to disturbances in the networks, fault and load impedance, mutual coupling effects between parallel lines, series capacitor for compensation, and effect of infeed or outfeed currents in branched terminal line is the main challenges in the advanced networks.

This paper will study each challenge alone and will introduce some of suggested methods for D.R to overcome each challenge. Finally, an example shall study protection of electrical network contains number of challenges happened at one time by D.R. Number of faults at different locations shall be studied with D.R to check the ability of the D.R with suggested solutions to protect this electrical network.

2. CHALLENGES LEAD TO ERRORS IN D.R MEASUREMENTS

D.Rs are subject to many challenges with respect to the nature of T.L, and this lead to overreach or underreach error in the D.R measurements. Among of these challenges are the following: 


\subsection{Power swing}

The power network may be subjected to stable or un-stable power swings due to continuous disturbances, which affect the D.R measurements and may cause unwanted operations. The load impedance, which under steady state conditions is not within the relay's operating characteristic, may through this enters into the relay's operating characteristic. These disturbances due to line switching, generator disconnection, and the loss or application of large blocks of load within a short period of time, result in sudden changes in electrical power, whereas the mechanical power input to generators remains relatively constant. Depending on the severity of the disturbance and the actions of power system controls, the system may return to a new equilibrium state (stable power swing). Disturbances could cause large separation of generator rotor angles, large oscillations of power flows and eventually loss of synchronism between groups of generators or between neighboring utility systems ( un-stable power swing) [1].

There are traditional detection methods of power swing based on the difference of the rate of change of the positive-sequence impedance or resistance. This method of differentiation is usually implemented using two measuring elements separated by some impedance $\Delta \mathrm{Z}$ and the use of a timer device as shown in Fig. 1.

When the measured impedance crosses the outer impedance unit of the relay characteristic, it starts the timer and it stops when it crosses the inner unit. It is based on the fact that it takes a certain time for the rotor angle to advance because of system inertias. The rate of change of the impedance phasor is slow during stable or unstable power swings. It takes a finite time for the generator rotors to change position with respect to each other because of their large inertias. On the contrary, the rate of change of the impedance phasor is very fast during a system fault [1]. During normal system operating conditions, the measured impedance is the load impedance, and its locus is away from the D.R protection characteristics. When a fault occurs, the measured impedance

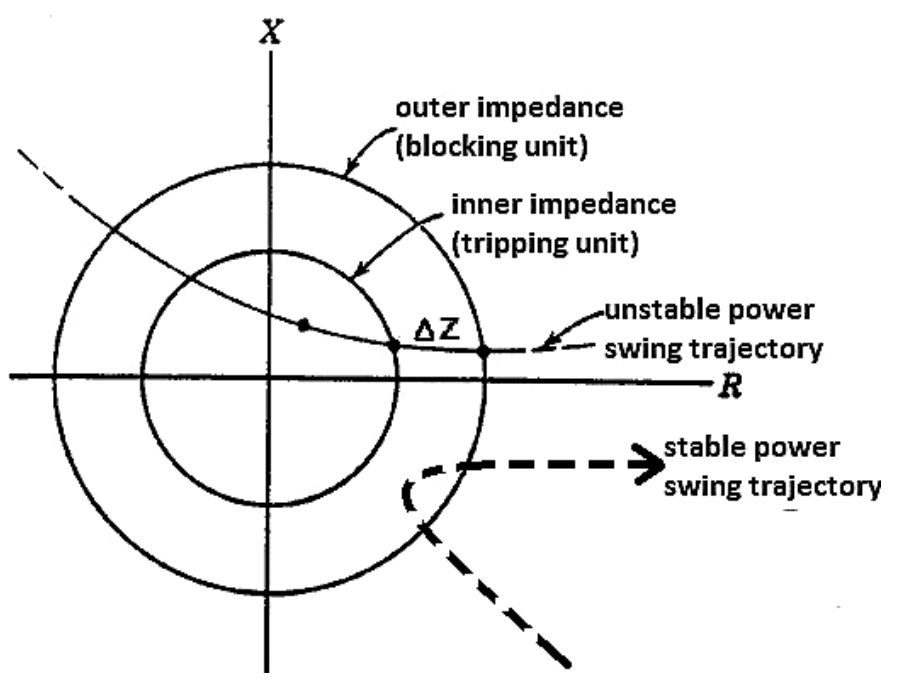

Fig. 1: Impedance Trajectories Of Stable And Unstable Power Swing Through Concentric Relay moves quickly from the load impedance location to the location that represents the fault on the impedance plane. So, the fault operates the second impedance element before the timer expires. During a system swing, the measured impedance moves slowly at some trajectory on the impedance plane. Its rate depends on the slip frequency between the machines. The timer expires before the impedance locus crosses the second impedance element and the rate of impedance change is determined by the slip frequency of an equivalent two-source system. This large difference in the speed of movement of impedance is used to differentiate between fault conditions and power swings.

It is important to avoid tripping of any power system element during stable power swings and protect the power system during unstable power swings. So it is important to detect power swings, differentiate between faults and power swings, and block D.R elements from tripping during power swings, it is referred to power swing blocking (PSB) function. It prevents system elements from tripping at random and at unwanted source-voltage phase-angle difference between systems that are in the process of losing synchronism with each other. When two areas of a power system, lose synchronism, the areas must be separated from each other quickly and automatically to avoid equipment damage and power system blackouts. The Out of Step Trip (OST) function accomplishes this separation so; the main purpose of it is to differentiate between 
the stable and unstable power swings. This shall initiate system area separation at the predetermined and preferred network locations and at the appropriate source-voltage phase-angle difference between systems. This shall maintain of power system stability and service continuity.

\subsection{Series compensated line:}

Recent transmission systems become more heavily loaded, then adding series capacitor is one of the cheapest, simplest ways of reduce the series inductive reactance of the line and enhance power transfer capacity. The introduction of series capacitors presents a number of technical challenges, when setting distance protection relays, because of the combined effects of the series capacitor's compensating reactance and the series capacitor's own protective equipment, on the measured impedance to a short-circuit fault as simplification in Fig. 2.

For the protection of serious capacitor, spark gaps, metal oxide varistors or circuit breakers which close during faults creating a bypass around the capacitor for high fault currents are used [2].

The dynamic changes that occur in the total impedance presented by the series capacitor and its protection devices are the main challenge which undermines the effectiveness of many of the protection schemes. This can cause the D.R to overreaching or under-reaching errors. Another challenge when the series capacitor has continuous changes in series capacitor location and degree of compensation.

One or more of these approached solutions shall be used to solve these challenges:

i. Slowing down (or delay) the operation of the relay so

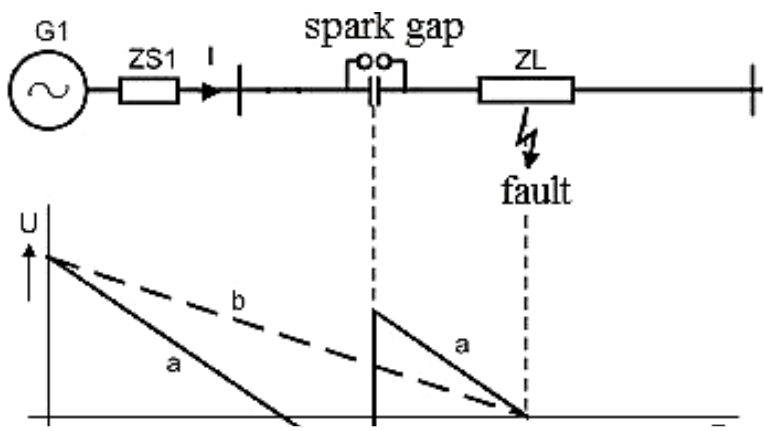

Fig. 2: Voltage characteristics where, line (a) without pickup of the protective sparks gap and

(b) with pickup of the protective spark gap. that the capacitor protection system will have time to operate and remove the capacitor from service, then the impedance calculation should be accurate [3].

ii. Using of phase comparison relaying with communications link, by comparing the phase angle of the current at one end of that line with the phase angle of the current at the other end of a line, it can be determined if there is a fault in the middle.

iii. Estimation of voltage drop or capacitor impedance using artificial neural networks to compensate for faults behind the capacitor [4].

iv. Reduction of the reach of the Zone 1-elements at about $30 \%$ of the line length, it is the simplest approach.

\subsection{Fault and load resistance:}

Fault resistance shall increase the value of the impedance measured by D.R and may bring it to underreach as from the relay characteristics shown in Fig. 3. The measured impedance shall be greater for earth faults more than multi-phase fault. For multi-phases fault, the fault consists of arc resistance only and appears as purely resistive in nature to result in a nearly constant voltage drop across the arc which approximately (4 to $5 \%$ ) of the driving system voltage, and the resistance varies inversely with the total current flowing in the arc. For earth faults, the fault may be grounded via a steel tower or tree. There may be an additional drop introduced through tower footing and grounding resistances, which are in series with the fault arc resistance. This resistive component does not vary inversely with the current, as the resistance in an arc; therefore, there could be a significant voltage drop across it.

The effect of fault resistance is most significant on short lines, where the reach of the relay setting is small. It can be a problem if the fault occurs near the end of the reach, then the D.R will see the fault with Zone 2 instead of Zone 1, but the more time of Zone 2 shall stretch the arc due to the wind. It shall use a reactance-type or modified-impedance type D.R to minimize the effect of fault resistance [6].

Arc characteristic can be calculated for a length equal to the distance between conductors for phase-to phase faults, 
or across an insulator string for phase-to-ground faults. One of the leading methods for calculating arc resistance for flexibility and for determining worst case values which added to the resistance reach by Warrington formula [7] where arc resistance is:

$$
R_{a}=\frac{28710 L}{I^{1.4}}
$$

$L$, the maximum phase conductor separation, and I, minimum fault current.

In case of heavy loads, the load impedance may be les $s$ than the D.R impedance reach and its trajectory may inter the relay operating characteristic. Yet, the protection must be made selective enough to discriminate between load and fault conditions. Traditional solutions by using one or more of the following:

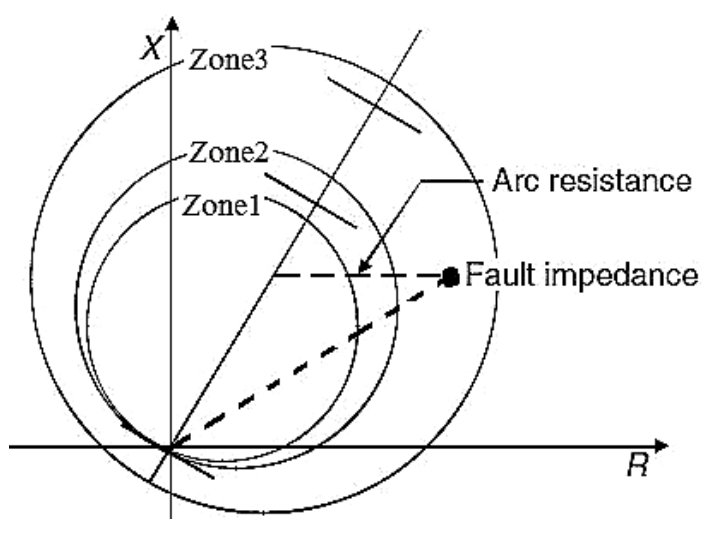

Fig. 3: Effect of arc resistance on the measured impedances $(\mathrm{Z1}, \mathrm{Z2}, \mathrm{Z3})$.

i. By reducing the fault coverage, so that the setting of high zones (especially Zone 3 which has the longest reach), that it's characteristic does not encroach on the load area by suitable margin.

ii. By using additional comparators to make blinders parallel to the T.L characteristic, to limit the impedance-plane coverage, and exclude load from the tripping characteristic.

iii. By using relays having different shaped characteristics (Circular, Lenticular, Figure of Eight, Trapezoidal or Elliptic).

Some of the modern line protection packages offer a much more optimal method of discerning between load and fault conditions. This feature, referred to as "load-encroachment", imposes more "knowledgeable" restrictions on distance element operation [8], [9].

iv. Adjustment the angle of maximum torque:

If the D.R operating characteristic is divided into several zones of protection (as Zone 1, Zone 2, and

Zone 3), so it is important to adjust the angle of maximum torque for each zone. The Angle of maximum torque of a simple mho unit (for example) is the angle at which it has its maximum reach. This angle is significant in two respective. It determines the amount of arc

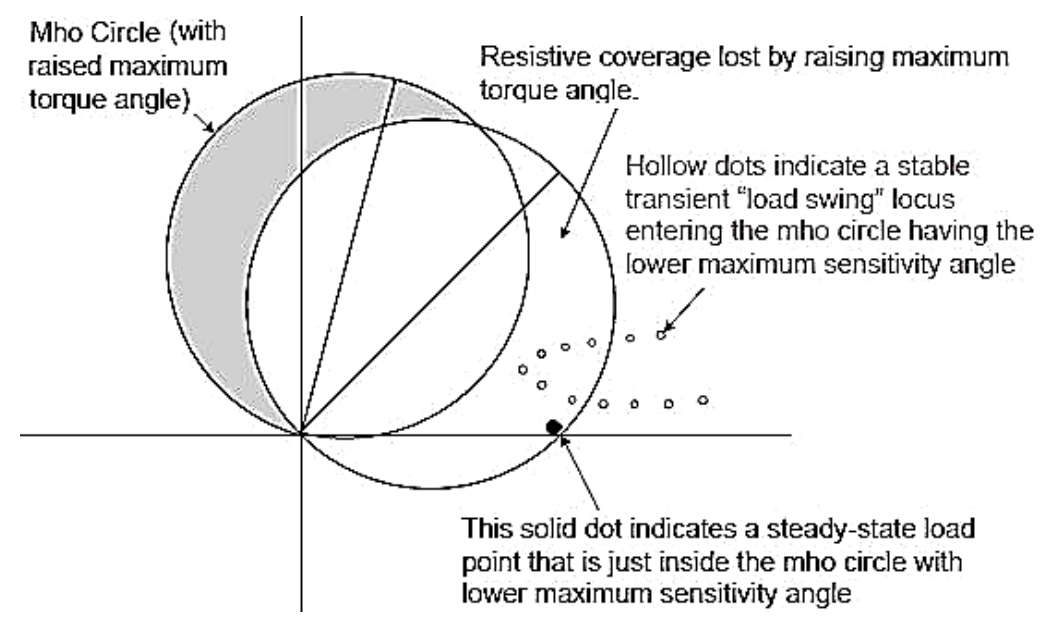

Fig. 4: Mho characteristic with different angle of maximum torque. resistance that can be accommodated by the unit, where the D.R unit with the smaller angle of maximum torque will accommodate a larger amount of arc resistance and where the unit with the large angle of maximum torque it is susceptible to operation on load or system swings.

Zone 1, will accommodate the least amount of arc resistance and will be least subjected to operate on system swing or heavy loads. Zone 2 and Zone 3 unit will accommodate the most arc resistance and will be most susceptible to operation on system swings or heavy loads. Thus where these factors are important, it may be desirable to use a Zone 1 unit with a relatively small angle 
of maximum torque while the Zone 2 and Zone 3 units have a larger maximum torque angle. This will permit the Zone 1 unit to accommodate more arc resistance and due to its short reach setting, its susceptibility to system swing will be minimized. On the other hand, due to the longer reach settings, the Zone 2 and Zone 3 units will accommodate considerable arc resistance, but their larger angles of maximum torque will minimize their susceptibility to system swings as shown in Fig. 4.

\subsection{Parallel T.L:}

Double circuit transmitting power is carried on transmission towers in narrow or wide physical corridors. The mutual coupling effect between lines, which varies with the line operating conditions and fault conditions is the main problem faced by conventional D.Rs, when applied on the parallel lines. Performance of D.Rs on double circuit lines are affected by the fault current flow in the parallel lines. It will induce voltage in the protected line due to mutual induction.

The mutual coupling effects between parallel lines caused by positive and negative sequence currents flowing in the parallel lines are very small and are considered to be negligible. However, the mutual coupling effects of zero sequence currents could be significant. It will induce voltage in the protected line. Thus the fault voltage measured by the D.R on the protected line would include this induced voltage, which causes the impedance measured by the relay to be higher or lower (depending on the polarity of the induced voltage) than the actual value [10].

In case of phase to ground faults there are zero sequence components of current flowing in the parallel line which introduces an error in the phase to ground impedance measured by the relay. Figure 4 illustrates the conventional distance as applied to protect the protected lines with mutual coupling. It is easy to calculate the percentage of errors $(\eta)$ on the impedance measured by D.R and compensate it by the following equation [11], [12]:

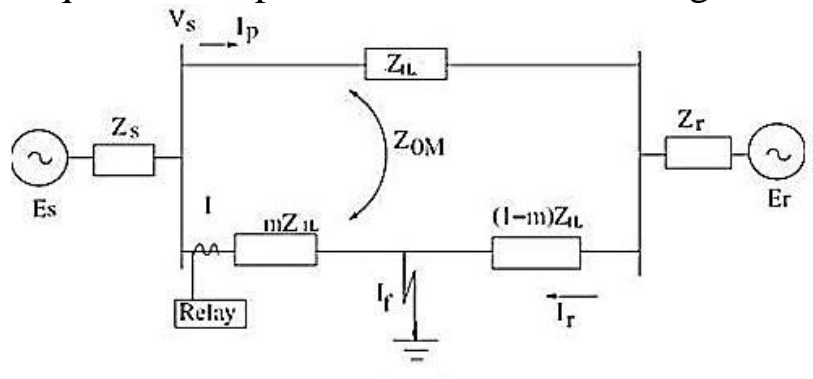

Fig. 5: Parallel T.Ls.

$$
\eta=\left(\frac{m\left(z_{0 M} / Z_{1 L}\right) I_{0 P}}{I_{a}+K_{0} I_{0}}\right), K_{0}=\left(\frac{Z_{0 L}-Z_{1 L}}{Z_{1 L}}\right)
$$

Where, $\left(\mathrm{K}_{\mathbf{0}}\right)$ is the line zero sequence current compensation or corrective factor whereas in case of phase to earth fault the part of $\left(\mathrm{K}_{0} \mathrm{I}_{0}\right)$ is added to the fault phase current $\left(\mathrm{I}_{\mathbf{a}}\right)$, then the D.R shall measures positive sequence impedance only, $\left(\mathrm{Z}_{1 \mathrm{~L}}\right)$ is the positive sequence impedance of the line, $(\mathrm{m})$ is the per-unit distance between the relay and the fault location and $\left(\mathrm{I}_{0}\right)$ is the fault zero sequence current at the relay location; $\left(\mathrm{Z}_{0 \mathrm{M}}\right)$ is the total zero sequence mutual coupling line impedance and $\left(\mathrm{I}_{0 \mathrm{P}}\right)$ is the parallel line's zero sequence current.

The error could be either positive or negative depending on the relative direction of parallel line's zero sequence current $\left(\mathrm{I}_{0 \mathrm{P}}\right)$ verses the compensated current $\left(\mathrm{I}_{\mathrm{a}}+\mathrm{K}_{0} \mathrm{I}_{0}\right)$. If they are in the opposite direction, the relay will overreach. If in the same direction, the relay will underreach. The overreach or underreach effect of conventional D.Rs, caused by the mutual coupling may be compensated by selecting proper relay settings provided the bus configuration, system impedance and line operating condition of a parallel line do not change during the normal operation.

Due to various reasons like load dispatch, forced outage, scheduled maintenance etc, operating condition of a parallel line could change from one to the other during the normal operations, so it is difficult to select relay settings to avoid possible false operation under the worst-case scenario, 
so it is important to develop the conventional D.Rs to adaptive type to minimize the effect of incorrect settings. It covers the wide range of power system condition thus increasing the accuracy and selectivity of the protection system.

The adaptive relaying scheme on each protected line accesses the three-phase voltage and current signals of the protected line. In addition, the zero sequence current and line operating status of the paralleled lines at the substation where the D.R is located will be used by the scheme. The scheme automatically adapts its operation based on the signal availability from the parallel lines to achieve an optimal performance by using the best available signals. If the parallel line's zero sequence current is available the scheme uses it first to compensate the mutual coupling effect in impedance measurement on faulted line [11]. For a phase to ground fault on the protected line, the correct fault impedance on the faulted line is:

$Z=\left(\frac{V_{a}}{I_{a}+K_{0} I_{0}+K_{0 m} I_{0 P}}\right)=m Z_{1 L}$

\subsection{Multi-Terminal T.L:}

The application of D.Rs to the protection of multi terminal lines is more complex than in case of using two terminal lines due to the infinite variety of tap locations, line impedances, source impedances, system loading requirements, and system operating conditions. These terminals may have outfeed or infeed currents. In case of outfeed the D.R will overreach and the impedance measured less than the actual impedance. In case of infeed, the D.R will underreach and the impedance measured more than the actual impedance [13].Simple model of multi terminal line is three terminal lines ( $\mathrm{T}$ line) is shown in Fig. 6.

To overcoming these errors, there are two main suggestions:

1) Dividing the D.R operating characteristics into several zones, at least three zones (Zone 1, Zone 2 and Zone 3) [10], [14].

Zone 1, is set to trip with no intentional time delay. The setting of Zone 1 is less than the full line impedance by suitable margin as $20 \%$ to prevent overreaching and to avoid unnecessary operation for faults beyond the remote terminal. In case of T-line, Zone 1 is set for the nearest terminal. The arc resistance has little effect on accuracy of Zone 1 unit as it operates instantaneously before the arc can stretch appreciably except in case of short lines.

Zone 2, is set to protect the remainder of the line plus an adequate margin as $20 \%$, and should be adjusted so that it will be able to operate in case of underreaching cases due to arc fault at the end of the line, the effect of intermediate current sources, errors in the data on which adjustments are based, the current and voltage transformers, and the relay inaccuracies. Typical time delays of Zone 2 unit are normally about (0.2-0.5) second, depending on the application. In case of multi terminal lines the reach of zone 2 at least $120 \%$ of the longest terminal. Under conditions of maximum overreach, Zone 2-reach should be short enough to be selective with the Zone 1 unit of the relay on the shortest adjoining line sections. In many applications it is common practice to set Zone 2-reach to be equal to the protected line section plus 50\% of the shortest adjacent line.

Zone 3, has forward and reverse reach. Zone 3 forward is applied as backup for Zone 2 and remote backup for relay at the remote terminal. It should be time delayed to coordinate with the 
remote Zone 1 and Zone 2 relays. Ideally the setting of Zone 3 relay shall cover the protected line, plus all of the longest line leaving remote station, with adequate margin and with consideration for underreach; namely, arcs and intermediate current sources in the branched terminals. The setting of Zone 3 forward is usually $120 \%$ of the protected line plus the longest adjoining line impedance; it must be less than Zone 2 of the remote relay.

Zone 3-reverse typically provides back-up protection for the local busbar, then the offset reach is set to $25 \%$ of the Zone 1-reach of the relay for short lines (less than $30 \mathrm{~km}$ ) or $10 \%$ of Zone 1reach for long lines in the backward direction. Its setting must satisfy the requirements for switch-on to fault case. If Zone 3-reverse is used to provide reverse directional decisions for blocking scheme, it must reach further than Zone 2 for the remote relay by an adequate margin [10].

2) By using Distance Protection Schemes:

There are two major categories of protection schemes for T.L, "Pilot Protection" and "Non-Pilot Protection" [10], [15].

Pilot protection schemes, the system involve relays at two or more substations that share data or logic status via a communication channel for improving the tripping speed. It uses a communications link between the ends of the line to be protected. The biggest problem with pilot protection schemes unfortunately is the communications channels. It may be PLC, fiber optic, copper, microwave, etc, are typically the weakest link in the system and most likely to contribute to the failure of the scheme. Furthermore, they are quite expensive to install and require more maintenance when compared to non-pilot schemes. These schemes include; Tripping, Blocking, Un-Blocking, and hybrid schemes as following.

1) Tripping protection schemes include the following:

i. Direct Under-reach Transfer Tripping Scheme (DUTT), where the fault must be seen by Zone 1-functions from at least one terminal. A contact operated by the relay Zone 1-element is arranged to send a signal to the remote relay requesting a trip, then DUTT scheme will provide near simultaneous tripping at all terminals. In (DUTT) a very secure signaling channel is required because of incorrect operation leads to false tripping, so it is not commonly used.

ii. Permissive Under-reach Transfer Tripping Scheme (PUTT), where the fault must be seen by the Zone 1-function from at least one terminal and trip this terminal and send signal to the remote terminal requesting to trip, at the remote terminal the received signal is supervised with the overreaching functions (Zone 2 relay element) from the other terminals before allowing an instantaneous trip.

iii. Permissive Under-reaching Acceleration Scheme (PUA) ), where the reach of the measuring elements is extended from Zone 1 to Zone 2 by means of a range change signal immediately, instead of after Zone 2 times. The under-reaching Zone 1 unit is arranged to send a signal to the remote end of the feeder in addition to tripping the local circuit breaker. The reception relay contact is arranged to extend the reach of the measuring element from Zone 1 to Zone 2. This accelerates the fault clearance at the remote end for faults that lie in the region between the Zone 1 and Zone 2 reaches.

iv. Permissive Over-Reach Transfer Tripping Scheme (POTT), where the instantaneous contacts of the Zone 2 unit are arranged to send signal, and the received signal, supervised by Zone 2 operation, is used to energize the trip circuit.

2) Blocking protection schemes is described as following:

Signaling is initiated only for external faults to prevent tripping of the local and remote terminal, and signaling transmission takes place over healthy line sections. The signaling channel is keyed by reverse looking distance elements. The reverse-looking elements and the signaling channel must operate faster than the forward-looking elements.

3) Un-Blocking protection schemes is described as following:

The block signals is transmitted continuously, when the over-reaching distance elements operate, the frequency of the signal transmitted is shifted to an 'unblock' (trip) frequency. The receipt of the unblock frequency signal and the operation of overreaching distance elements allow fast 
tripping to occur for faults within the protected zone. It is made more dependable than the permissive over-reach scheme by providing additional circuits in the receiver equipment. These allow tripping to take place for internal faults, even if the transmitted unblock signal is shortcircuited by the fault. Typically 100 to 150 milliseconds, after the loss of both the block and the unblock frequency signals. After this time interval, aided tripping is permitted only if the unblock frequency signal is received. This arrangement gives the scheme improved security over a blocking scheme, since tripping for external faults is possible, only if the fault occurs within the above time interval of channel failure. In this way, the scheme has the dependability of a blocking scheme and the security of a permissive overreach scheme. This scheme is generally preferred, when power line carrier is used, except when continuous transmission of signal is not acceptable.

4) Hybrid Scheme is described as following:

It is a balance of the security of the Permissive Overreaching Transfer Trip scheme and the dependability of the Blocking scheme. It requires both permissive overreaching and blocking functions.

For Non-Pilot protection schemes, there is no data sharing between relays, it requires no pilot communication channels. This is a tremendous cost savings to begin with as none of these methods are cheap. There are two schemes:

a) Time-stepped distance protection scheme; using sequence of Zone1, Zone 2, and Zone 3.

b) Zone 1 extension scheme; Zone 1 elements of the D.R have two settings. The first as Zone 1 is set to cover $80-90 \%$ of the protected line length. The other, known as Extended Zone, is set to overreach the protected line and normally extended in reach setting to cover $120 \%$ of the protected line to see beyond the remote terminal of the T.L. The extension of the Zone 1 functions is controlled by an output from an automatic reclosing relay, which is required to implement the scheme.

To represent the D.R setting at the worst case it is important to implement it with network has more than one challenge. From previous representation in this paper, it is easy to use the D.R when the protected network are subjected to challenges by dividing the D.R operating characteristic into zones and calculating each zone value alone, then re-setting the D.R with these values and by using protection schemes to implement the protection. This suggested solutions and other solutions for D.R to overcome each challenge as seen in the following examples.

\section{Example:}

The chosen network is a part of South Sinai EHVpower network. This network is subjected to more than one challenge simultaneously. It is composed of parallel lines with branched T.L (T-line) under construction to feed New Sharm El-Sheikh City and the fault is having considered arc and foot resistance. The length of T.L

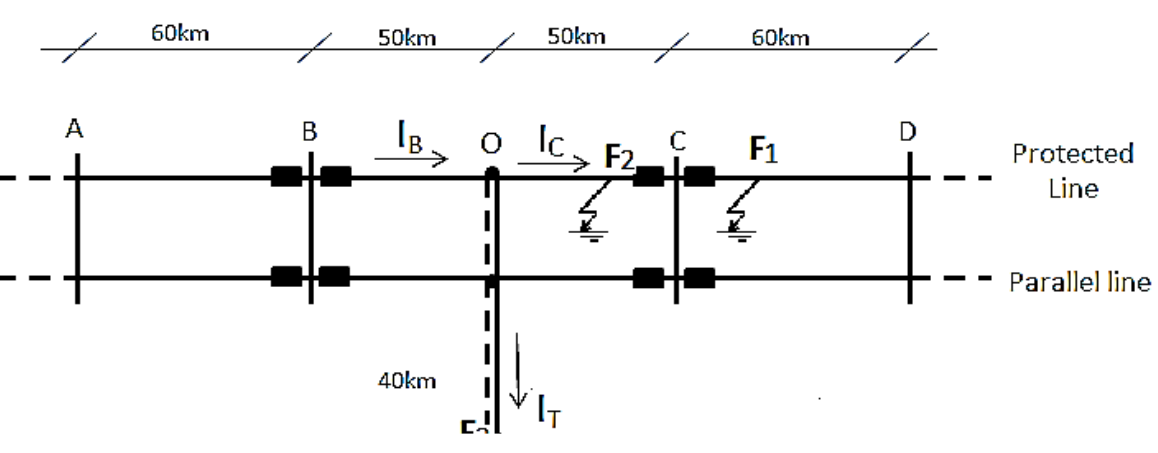

Fig. 7: Part of the network under study with different faults in different sections. sections with different suggested

faults locations are shown in Fig. 7. The protected section is $100 \mathrm{~km}$ double circuit line between $\mathrm{B}$ and $\mathrm{C}$ substations with branched terminal of OT using D.R type (Seimens-7SA511). The D.R at bus $\mathrm{B}$ of the protected line shall be considered.

The T.L parameters are obtained from the Egyptian Company for Electrical Transmission as shown in Table 1. 
Table 1: T.L parameters.

\begin{tabular}{|l|l|l|l|}
\hline $\mathrm{Z}_{1}=(0.089+\mathrm{j} 0.476) \Omega / \mathrm{km}$ & $\mathrm{I}_{\mathrm{T}}=50.20 \mathrm{~A}$ & $\mathrm{Z}_{\min }=13.3 \Omega$ & Zone $2_{(\mathrm{C})}=5.2272 \angle 80 \Omega^{\circ}$ \\
\hline $\mathrm{Z}_{0}=(0.426+\mathrm{j} 1.576) \Omega / \mathrm{km}$ & $\mathrm{I}_{\mathrm{B}}=301.2 \mathrm{~A}$ & $\mathrm{R}_{\text {foot }}=10 \Omega$ & Zone $1_{(\mathrm{C})}=2.788 \angle 80 \Omega^{\circ}$ \\
\hline $\mathrm{Z}_{0 \mathrm{M}}=(0.107+\mathrm{j} 0.571) \Omega / \mathrm{km}$ & $I_{m}=1.8 \mathrm{KA}$ & $\Delta \mathrm{R}=2.128 \Omega$ & $(\mathrm{CT} / \mathrm{VT})=0.12, \mathrm{~L}=10 \mathrm{~m}$ \\
\hline
\end{tabular}

Where,

$\mathrm{Z}_{1}, \mathrm{Z}_{0}$ : Primary Positive and Zero sequence impedances,

$\mathrm{Z}_{0 \mathrm{M}}$ : Zero sequence mutual impedance between two parallel lines.

$\mathrm{R}_{\text {foot }}$ Tower Footing resistance, (CT/VT): Current to Voltage Transformer ratio.

$\Delta \mathrm{R}$ : Separation resistance between power swing concentric characteristics.

$I_{m}$ : Minimum fault current at substation B, L: Maximum phase conductor separation.

$\mathrm{I}_{\mathrm{T}}, \mathrm{I}_{\mathrm{B}}$ : Curents in BO and OT sections at maximum load, $\quad \mathrm{Z}_{\mathrm{min}}: \quad$ Minimum $\quad$ load impedance.

Zone $2_{(\mathrm{C})}$ : Zone 2 of D.R at bus $\mathrm{C}$ which protects section $\mathrm{CD}$.

Zone $1_{(\mathrm{C})}$ : Zone 1 of D.R at bus $\mathrm{C}$ which protects section $\mathrm{CD}$.

The actual positive sequence impedance of T.L sections have been calculated in Table 2 without the effect of any challenge or considering any assumed fault in the T.L.

Table 2: Positive sequence secondary impedance and length of T.L sections.

\begin{tabular}{|c|c|c|c|c|c|}
\hline T.L Sections & AB & BC & CD & OT & BOT \\
\hline Length $(\mathrm{Km})$ & 60 & 100 & 60 & 40 & 90 \\
\hline $\begin{array}{c}\text { Actual } \\
\text { Impedance }(\Omega)\end{array}$ & $\mathbf{3 . 4 8 5} \angle 80^{\circ}$ & $\mathbf{5 . 8 1} \angle 80^{\circ}$ & $\mathbf{3 . 4 8 5} \angle 80^{\circ}$ & $2.3232 \angle 80^{\circ}$ & $5.2272 \angle 80^{\circ}$ \\
\hline
\end{tabular}

The apparent impedance is the value seen by D.R with considering challenges presented in the network. In our case, each actual and apparent impedance are calculated with respect to given example data. The errors in measurements (overreach or underreach) are occurred when the sections are subject to challenges as T-line, arc or load resistant and mutual impedance due to parallel lines.

Avoiding these errors in measurements as following:

1) Effect of infeed or outfeed currents on the D.R measured impedance:

To overcome this effect, D.R operating characteristics shall be divided into three zones of operation (Zone 1, Zone 2 and Zone 3). Each zone shall be calculated at its worst case. Zone 1 is calculated to avoid the effect of overreach errors in measurement due to outfeed currents, Zone 2 is calculated to avoid the underreach errors, and Zone 3 is calculated as backup for Zone 1 and Zone 2 as shown in this paper in section 2.5.

a) Required Zone 1 reach: Since the section BOT is less than BC, then Zone 1 is adjusted on section BOT, then Zone 1 (equal to $80 \%$ of $Z_{\text {Вот }}$ ) $=4.182 \angle 80^{\circ} \Omega$

Zone 1-reach shall be checked with the worst case condition, where if there are outfeed current at point $\mathrm{O}$ which cause the D.R at $\mathrm{B}$ to overreach in case of fault at remote bus $\mathrm{C}$, then the D.R will measure, $Z_{R}=Z_{B O}+Z_{O C}-\left(\frac{I_{T}}{I_{B}}\right) Z_{O C}=5.326 \angle 80^{\circ} \Omega$

The value of Zone 1 in Eq. (5) is more than the value in Eq. (4), then Zone 1 in Eq. (4) is correct. 
b) Required Zone 2 reach: Since the section BC is longer than BOT, then Zone 2 is adjusted on section $\mathrm{BC}$, then Zone 2 (equal to $120 \%$ of $B C$ ) $=6.972 \angle 80^{\circ} \Omega$

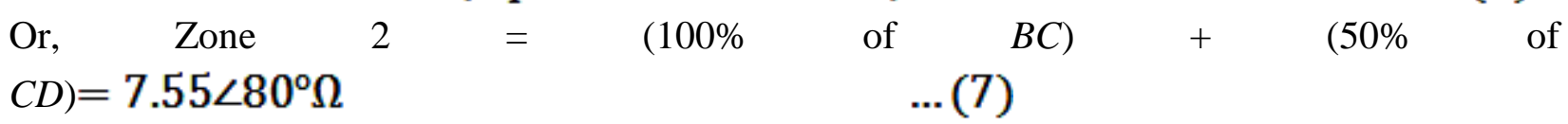

The value of Zone 2 in Eq. (7) is more than the value in Eq. (6), then Zone 2 in Eq. (7) is correct. But Zone 2 of the D.R at bus B shouldn't exceed the margin of Zone1 ${ }_{(\mathrm{C})}$, ((Zone 2 in Eq. 7) should less than $\left(\right.$ Zone $\left.1_{(c)}+Z_{B C}\right)$ ), then the setting of Zone 2 in Eq. (7) is correct.

It is important to take the effects of parallel line on Zone 2 reach, where Parallel line may have an infeed current and can cause the D.R measured impedance to underreach if the fault lies at the remote section (CD), but any fault take happen at remote section (CD) shall eliminate by D.R at bus $\mathrm{C}$ which protect section $\mathrm{CD}$.

a) Required $Z_{3}$ (forward) reach (equal to $120 \%$ of $\left.\left(Z_{B C}+Z_{C D}\right)\right)=11.154 \angle 80^{\circ} \Omega$

A worst case happened, when the parallel line CD is switched off and fault is occurred at protected line of section $\mathrm{CD}$ at point $\mathrm{F}_{1}$ (for example), then there is an infeed current from parallel line $\mathrm{BC}$ as shown in Fig. 8, then

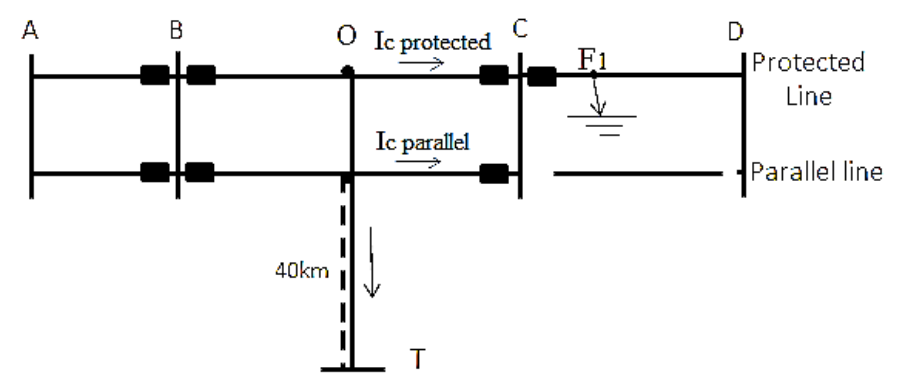

Fig. 8: Fault $\left(F_{1}\right)$ occurs at protected line $C D$ when parallel line has been opened.

Zone3 $=120 \%$ of $\left(Z_{B C}+Z_{C D}+\right.$ error $)$

Since, error $=Z_{C D} \times\left(\frac{I_{C \text { parallel }}}{I_{C \text { protected }}}\right), I_{C \text { parallel }}=I_{C \text { protected }}$, then

error $=3.485 \angle 80^{\circ}$, then Zone $3=15.34 \angle 80^{\circ} \Omega$

Since, Zone 3 (forward) shouldn't exceed the margin of Zone $2_{(\mathrm{C})}$, then Zone 3 (forward) should less than $\left(\left(\right.\right.$ Zone $\left.\left.2_{(c)}+Z_{B C}\right)=11.04 \angle 80^{\circ}\right)$ so, Zone 3 will be reduced to $\left(11.04 \angle 80^{\circ} \Omega\right)$. If it not possible, then time grade to Zone 3 should be added.

b) Required Zone 3 (reverse) reach setting should more than or equal to $110 \%$ of Zone 2 reach of the remote D.R at bus C (which protect section $C B$ ) minus the protected line impedance $\left(\mathrm{Z}_{\mathrm{CB}}\right)$.

Since, Zone 2-reach of the remote D.R $=\left(Z_{C B}\right)+\left(50 \%\right.$ of $\left.Z_{A B}\right)=7.55 \angle 80^{\circ} \Omega$, then

Required Zone 3 (reverse) reach $=7.55 \angle 80^{\circ}-Z_{C B}=2.495 \angle 80^{\circ} \Omega$

The setting values of D.R zones at bus B of the protected line is given in Table 3. 
Table 3: Setting values of D.R zones located at bus B in ohm.

\begin{tabular}{|c|c|c|c|}
\hline Zone 1 & Zone 2 & Zone 3(forward) & Zone 3(reverse) \\
\hline $\mathbf{4 . 1 8 2} \angle 80^{\circ}$ & $\mathbf{7 . 5 5} \angle 80^{\circ}$ & $\mathbf{1 1 . 0 4} \angle 80^{\circ}$ & $2.495 \angle 80^{\circ}$ \\
\hline
\end{tabular}

Due to the symmetry in the T.L impedances, the settings values of D.R located at bus $\mathrm{C}$ for section BC are equal to the settings of D.R at bus B. After calculation the D.R zones, it is important to use one of operating characteristic schemes as POTT scheme (section 2.5).

2) Effect of mutual impedance between parallel lines on the D.R measured impedance: This impedance causes the impedance measured by the relay to be higher or lower (depending on the polarity of the induced voltage) than the actual value. From section 2.4, then for phase to ground faults on the protected line with using adaptive D.R, from Eq. 2, it is important to use current and mutual impedance compensation factors $\left(\mathrm{K}_{0}, \mathrm{~K}_{0 \mathrm{~m}}\right)$ with the D.R impedance measured, then the correct fault impedance measured by D.R is:

$$
\begin{aligned}
& Z=\left(\frac{V_{a}}{I_{a}+K_{0} I_{0}+K_{0 m} I_{0 P}}\right)=m Z_{1 L}, \\
& K_{0}=\left(\frac{Z_{0}-Z_{1}}{Z_{1}}\right)=\frac{(0.426+\mathrm{j} 1.576)-(0.089+\mathrm{j} 0.476)}{(0.089+\mathrm{j} 0.476)}=2.37 \angle-6.5^{\circ}, K_{0 m}=\left(\frac{Z_{0 M}}{Z_{1 L}}\right)=\frac{(0.1}{(0.0}
\end{aligned}
$$

3) Effect of fault and load resistance on the D.R zones:

The setting values of D.R should be more than the values of fault resistance and less than the values of load resistance. If a fault resistance due to arc and tower footing resistance is considered, from Eq. 1, then

$$
R_{\text {arc }}=\left(\frac{27810 \mathrm{~L}}{I_{m}{ }^{1.4}}\right)=\frac{27810 \times 10}{1800^{1.4}}=7.7 \Omega(\text { primary })=0.924 \Omega \text { secondary }
$$

The fault resistance $(R)=R_{\text {arc }}+R_{\text {foot }}=0.924+1.2=2.124 \Omega$

The resistance part of D.R zones must be more than the fault resistance $(2.124 \Omega$ ) and less than the minimum load resistance $(13.3 \Omega$ ) by suitable margin as $(20 \%)$. If there is possibility of power swing occurring, then the minimum load impedance must be reduced by separation resistance value between power swing concentric characteristic $(\Delta \mathrm{R})$, then maximum resistive reach of D.R zones $=0.8(13.3-2.128)=8.9 \Omega$ ... (14)

Then the real part of higher zone (Zone 3) shall be less than or equal to $8.9 \Omega$ as shown in Fig. 9. The

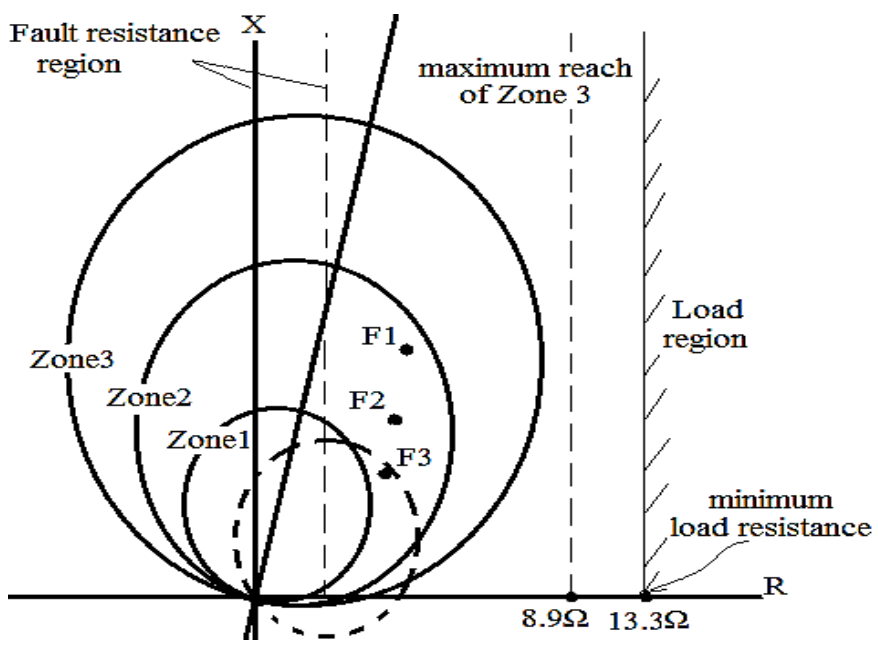
values of D.R operating characteristic zones are Fig. 9: Three zones with load and fault resistance margin. represented in Table 3 and Fig. 9. The D.R will protect correctly the fault impedance which lies 
in these operating characteristic zones. It is important to increase the zone coverage by decrees angle of maximum torque as mentioned previously in this paper.

4) Checking the ability of the D.R operating characteristic Zones calculated at buses B and C by assuming faults $\left(F_{1}, F_{2}\right.$ and $\left.F_{3}\right)$ as shown in Fig. 7 , where $F_{1}$ located at $\left(25 \%\right.$ of $\left.Z_{C D}\right), F_{2}$ at $\left(75 \%\right.$ of $\left.Z_{\mathrm{BC}}\right)$, and $\mathrm{F}_{3}$ at $\left(90 \%\right.$ of $\mathrm{Z}_{\mathrm{OT}}$ ). The measured and actual impedance values of D.R for these faults are calculated theoretically, then the impedance measured at bus B for fault at points of $F_{1}, F_{2}$, and $F_{3}$ as shown:

- At $\mathrm{F}_{1}$, then

$$
\begin{aligned}
Z_{\text {actual }} & =Z_{B C}+Z_{C F 1}=Z_{B C}+\left(0.25 \times Z_{C D}\right) \\
& =6.68 \angle 80^{\circ} \Omega
\end{aligned}
$$

Since, $Z_{\text {measured }}=Z_{\text {actual }}$-error,

$$
\text { error }=\left(\frac{I_{T}}{I_{B}}\right) Z_{O F 1}=\left(\frac{I_{T}}{I_{B}}\right)\left(Z_{O C}+Z_{C F 1}\right)=0.628 \Omega
$$

Then,

$Z_{\text {measured }}=6.05 \angle 80^{\circ} \Omega$

If fault resistance $(R)$ is taken into our consideration then,

$Z_{\text {measured }}=6.05 \angle 80^{\circ}+2.124 \angle 0=6.75 \angle 61.96 \Omega$

- At $\mathrm{F}_{2}$, then

$$
Z_{\text {actual }}=0.75 \text { of } Z_{B C}=4.36 \angle 80^{\circ} \Omega
$$

Since,

$Z_{\text {measured }}=Z_{\text {actual }}$-error \& error $=\left(\frac{I_{T}}{I_{B}}\right) Z_{\text {OF2 }}=\left(\frac{I_{T}}{I_{B}}\right)\left(0.25 \times Z_{B C}\right)=0.24 \angle 80^{\circ} \Omega$

\section{Then,}

$Z_{\text {measured }}=4.12 \angle 80^{\circ} \Omega$

If fault resistance $(R)$ is taken into our consideration then,

$\mathrm{Z}_{\text {measured }}=4.12 \angle 80^{\circ}+2.124 \angle 0=4.95 \angle 55 \Omega$

- At $\mathrm{F}_{3}$, then

$$
Z_{\text {actual }}=Z_{B O}+Z_{O F 3}=Z_{B O}+\left(0.9 X Z_{O T}\right)=4.993 \angle 80^{\circ} \Omega
$$

Since,

$Z_{\text {measured }}=Z_{\text {actual }}-$ error \& error $=\left(\frac{I_{C}}{I_{B}}\right) Z_{O F 3}=\left(\frac{I_{B}-I_{T}}{I_{B}}\right) Z_{O F 3}=1.74 \angle 80^{\circ} \Omega$

Then, $\quad Z_{\text {measured }}=3.253 \angle 80^{\circ} \Omega$

If fault resistance $(R)$ is taken into our consideration then,

$$
\mathrm{Z}_{\text {measured }}=3.253 \angle 80^{\circ}+2.124 \angle 0=4.179 \angle 50 \Omega
$$


Table 4: Measured and actual impedances which are calculated for faults $F_{1}, F_{2}$ and $F_{3}$.

\begin{tabular}{|c|c|c|c|}
\hline Fault Symbol & $\mathrm{F}_{1}$ & $\mathrm{~F}_{2}$ & $\mathrm{~F}_{3}$ \\
\hline Fault Position $(\%)$ & $25 \%$ of $Z_{\mathrm{CD}}$ & $75 \%$ of $Z_{\mathrm{BC}}$ & $90 \%$ of $Z_{\mathrm{OT}}$ \\
\hline Actual Impedance $(\Omega)$ & $6.68 \angle 80^{\circ}$ & $4.36 \angle 80^{\circ}$ & $5 \angle 80^{\circ}$ \\
\hline Measured Impedance $(\Omega)$ & $6.75 \angle 61.96$ & $4.95 \angle 55$ & $4.179 \angle 50$ \\
\hline
\end{tabular}

Values of $F_{1}, F_{2}$ and $F_{3}$ are represented in Fig. 9 with three zones of D.R. It is important to compare the measured impedance of each fault in Table 4 with setting of D.R zones in Table 3, then

$\mathrm{F}_{1}$ is protected by Zone 2 and Zone 3 of relay at bus $\mathrm{B}$ and by Zone 1 at the relay at bus $\mathrm{C}$ which protects the section of $\mathrm{CD}$, but since Zone 1-time is less than Zone 2-time, then the fault is isolated by Zone 1 of relay at bus $\mathrm{C}$ for section $\mathrm{CD}$.

$\mathrm{F}_{2}$ is protected by Zone 2 and Zone 3 of relay at bus $\mathrm{B}$ and by Zone 1 at the relay at bus $\mathrm{C}$ for section $\mathrm{CB}$, so the time needed to eliminate the fault at relay at bus $\mathrm{B}$ is more than the time for relay at bus $\mathrm{C}$, then there are non-simultaneous opening of the circuit breakers at both ends of the faulted section results in no 'dead time' during the auto-reclose cycle.

$\mathrm{F}_{3}$ is protected by Zone 2 of the relay at bus $\mathrm{B}$, and by Zone 2 of the relay at bus $\mathrm{C}$ (due to symmetry of the T.L). Due to large fault resistance, then the fault don't seen by Zone 1, so it is important to decrees the maximum of angle torque for Zone 1 to cover the fault at $\mathrm{F} 3$ as shown in Fig 9. By using any distance protection schemes such as (POTT) with communication channel, its increase the security and dependability of D.R protection.

\section{CONCLUSIONS}

D.R is used in protection of electrical networks to measure the impedance from its location to any fault location on the T.L. Due to some of the network challenges, the impedance measured by the D.R may be differ for the actual impedance, then the measured impedance has errors (overreach underreach), and the D.R may be lead to false trip. These errors is due to some of challenges in the network as power swing, serious capacitor, mutual impedance due to parallel lines, fault and load impedances, and infeed or outfeed currents in branched terminals. Each one of these challenges has approached solutions to compensate it.

In this paper, each challenge alone shall be studied, and shall be introduced suggested methods for compensate each one as shown in the example studied in this paper. Slow down the D.R operation is the main suggested solution for series capacitor effect, reducing the D.R operating Zones by suitable margin is the main suggested solution for fault and load resistance challenge, adding zero sequence current factor and zero sequence mutual impedance factor to currents in the parallel or protected lines is the main suggested solution for compensation of mutual coupling effects between parallel lines, using the rat of change of positive sequence impedance of the fault trajectory between two measuring elements and using PSB and OST is the main suggested solution for detect and avoid the power swing effects, and dividing the D.R operating characteristics into several zones of operation and using distance protection schemes with or without communication channels is the main suggested solution for infeed or outfeed currents flow in the branched line. This approaches increase the D.R dependability and security of the D.R when it used with protection of electrical network contains some of challenges.

The example taken in this paper studied how D.R may be used to protect an electrical network contains number of challenges happened at one time by using the suggested solution mentioned previously, and finally the example suggested number of faults at different locations to check the ability of the D.R with these suggested solution to protect this electrical network which be studied.

\section{REFERENCES}

[1]. Mike McDonald, "Power swing and out-of-step Considerations on transmission lines," IEEE PSRC WG D6, 2005. 
[2]. M. Zellagui, A. Chaghi "MHO distance relay of Transmission line high voltage using series compensation in Algeria network," Acta Electrotehnica, pp 126-133, 2011

[3]. Clint T. Summers, "Distance Protection Aspects of Transmission Lines Equipped with Series Compensation Capacitors," Faculty of the Virginia Polytechnic Institute and State University for the degree of Master in Electrical Engineering, 1999.

[4]. M. M. Sara, B. Kasztenny, E. Rosolowski, J. Izykowski, "First Zone Algorithm for Protection of Series Compensated Lines", IEEE Transactions on Power Delivery, Vol.16, No. 2, 2001.

[6]. C. Russell Mason "The art and science of protective relaying," Multilin.

[7]. Seppo Hänninen, "Single phase earth faults in high impedance grounded networks

Characteristics, indication and location", VTT publications, Espoo, 2001.

[8]. L.G Hewitson, Mark Brown, Ramesh, Balakrishnan, "Practical Power Systems Protection", Newnes, First published, 2004.

[9]. J. Lewis Blackburn\& Thomas J. Domin, "Protective Relaying (Principles and Applications)," Taylor \& Francis Group, Third Edition, New York, 2006.

[10]. J. G. Andrichak, G.E. Alexander "Network Protection \& Automation Guide," Alstom Grid, Stafford UK, 2011.

[11]. S.G. Srivani, Chandrasekhar Reddy Atla, K.P.Vittal, "Comparative Evaluation of Adaptive and Conventional Distance Relay for Parallel Transmission Line with Mutual Coupling," World Academy of Science, Engineering and Technology, Vol: 18, 2008.

[12]. Ulrich Klapper "Measurement of line impedances and mutual coupling of parallel lines,"

Relay Protection and Substation Automation of Modern EHV Power Systems, Cigre Publication, Moscow - Cheboksary, 2007.

[13]. J. G. Andrichak, G.E. Alexander "Application of Phase and Ground Distance Relays to Three Terminal Lines," GE Publication GER-3964, Malvern, PA.

[14]. Jon F. Daume, "Distance Relays 101," 30th Annual Hands-On Relay School, Bonneville Power Administration, 2013.

[15]. "Draft guide for protective relay applications to transmission line," IEEE PC37.113/D1.0, NewYork, 2006. 